\title{
Introduction to Research Handbook on EU Media Law and Policy: understanding the EU approach to media law and policy. The scope of the Handbook and a presentation of the contributions
}

\author{
Pier Luigi Parcu and Elda Brogi
}

\section{MEDIA REGULATION AND THE EUROPEAN UNION}

Defining EU media law, and the broader concept of EU media policy, is more challenging today than in the past, and inevitably includes dealing with the construction and interpretation of the regulation of digital services, also in a de iure condendo perspective. It must be stressed, that the field of digital services regulation not only affects an increasingly decisive economic sector, but goes beyond mere market issues, investing the social and political significance of media and "non-media" platforms. ${ }^{1}$ In fact, the media ecosystem has faced an obvious metamorphosis and a deep disruption over the last three decades. The extraordinary evolution of audiovisual and communication services has probably precipitated the conditions for wider EU intervention and jurisdiction in a field where national member states, taken in isolation, risk being overwhelmed. ${ }^{2}$

This is a primary reason why the Handbook will have to explore and compare several pieces of European legislation having an impact on the "media" sector, defined in a broad sense for its capacity to influence the public opinion at large. Among those different legal fields reaching toward the media, we can immediately list: competition rules, rules on electronic communications, rules on e-Commerce, data protection regulation, copyright, to mention only the most important. All this essentially indirect influence exercised by many EU legal fields

\footnotetext{
1 Natali Helberger, 'The Political Power of Platforms: How Current Attempts to Regulate Misinformation Amplify Opinion Power' (2020) 8 Digital Journalism 842.

2 It must be acknowledged that, at national level, two countries in the EU are trying to set the standards for a new path in the regulation of digital services, Germany and France. Outside the EU, the United Kingdom as well is experimenting with a regulatory policy based on the so-called "duty of care" of online platforms. Germany started, with the German Network Enforcement Act, to build on the logic of the e-Commerce directive, with a focus on enforcing the existing intermediary obligations, and more recently with adding media pluralism obligations to the Interstate Media Treaty (see Jan Christopher Kalbhenn 'New Diversity Rules for Social Media in Germany' (Centre for Media Pluralism and Freedom, 21 February 2020) <https://cmpf.eui.eu/new-diversity-rules-for-social-media-in-germany/> accessed 21 December 2020.). As mentioned by Helberger (n. 1), "The German approach, combined with the revised European Audiovisual Media Services Directive, signals an important point of departure from the traditional European e-Commerce approach to the regulation of social media ... and a move into a media law regime".
} 


\section{Research handbook on EU media law and policy}

(and policies) on the media should not be undervalued or confused with a lack of impact. Never before, considering the current trends in the media and media-related markets, has the importance of the EU in determining the rules and policies of the European "media" sector, in the broad definition used in this Handbook, been so relevant and necessary.

The Handbook will attempt to explain EU media policy by successive approximations, moving from the general to the specific. It will first examine certain fundamental pillars of EU legal assets that undoubtedly contribute to characterise the action of the European Union in the industry. Secondly, it will move to other fields of legislation, where a series of "sectoral" rules, while pursuing their different targets, also affect and shape the media. Afterwards, several contributions will zoom in on the EU legislation, essentially the Audiovisual Media Service Directive (AVMSD), that effectively has the purpose to harmonise certain elements of the EU single market of audiovisual services and constitutes the core of the EU specific acquis on media. In its final Part, the Handbook introduces some wider policy themes in an attempt to interpret EU's efforts to guide the powerful change that media is undertaking in the EU and beyond.

In recent decades, the simultaneous propagation of technological advancements, the development of the Internet, the digitalisation of the media industry, the consequences of the widespread liberalisation policies across Europe, as well as the trends of globalisation, have combined to induce and amplify a digital revolution of the media sector. The latter has undoubtedly allowed a number of positive developments, particularly the ability to cheaply, quickly and efficiently, produce and share information on a much larger scale, widening the choices of users and boosting innovative business models rooted in the new digital ecosystem. While technological advancements have created new opportunities for European citizens to be informed by different and plural sources, they have also prompted new risks. The viral spread of disinformation and hate speech on an unprecedented scale; a lack of transparency in algorithm-driven news intermediaries; the increasing importance of private technological companies in governing communication online; the polarisation of public debate; the decreasing sustainability of the legacy news media and journalism are all elements that can impact the functioning and the legitimacy of any democracy in Europe and necessitate a common response at EU level. ${ }^{3}$

In the digital ecosystem the same definition of "media" is an issue of debate amongst academics and policymakers. In the past, the term was easily associated with press and broadcasting. Therefore, media law and regulation were historically based on and justified by their potential impact on society, and on the individual rights, in relation to mass communication. Regulating the media sector was seen as necessary for the public's interest, particularly for broadcasting, an industry that needs significant economic resources and the availability of assets (e.g. frequencies) that are fundamentally scarce. ${ }^{4}$ This public interest was so strongly perceived that in European countries it justified, at least at the beginning of the industry, the establishment of state monopolies of broadcasting.

A key aspect of the digital revolution has been the so-called technological "convergence". The aspect of convergence that most affects the present research refers to the progressive

3 Pier Luigi Parcu, 'New Digital Threats to Media Pluralism in the Information Age' (European University Institute 2019) Working Paper <https://cadmus.eui.eu//handle/1814/61890> accessed 7 December 2020.

4 Denis McQuail, McQuail's Mass Communication Theory (Sage Publications 2000). 
blurring of boundaries between established media and other communication industries. Media services that in the past could have been distributed only by predefined platforms (e.g. newspapers or mass media broadcasting) now are ubiquitously distributed using multiple digital technologies. ${ }^{5}$

A number of new "intermediaries" today, which typically pertain to the information and communication sector, play an essential role in determining media content's outreach. Services provided by these actors have become essential to find all types of information, and progressively turned these digital intermediaries into gatekeepers that play an active and decisive role in all mass communication processes. At first, these information services have complemented traditional media actors in determining media processes. Presently, it is unquestionable that certain big digital intermediaries/platforms have developed such influential and popular services, applications and/or algorithms, that they are directly able to influence the public's opinion, with national and global consequences. ${ }^{6}$ The companies that have developed these online platforms have become powerful and dominant in their markets, exploiting the opportunities provided by the Internet to progressively become quasi monopolists at a global level. ${ }^{7}$

These colossal digital platforms also facilitate, or even induce, users' participation in the creation process of news and in the dissemination of information and content, blurring another boundary between public and private communication, allowing mass and narrow audiences to essentially coexist. Consequently, in this twenty-first century digitally revolutionised information landscape, one observes the juxtaposition between the historical system of "mass media" and a new system of one-to-one communication that relies on "narrowcasting" but evolves in a sort of a previously unknown mechanism of many-to-many communications. In this new environment, tailor-made content is provided to individual users, while information about them is simultaneously collected through consistent consumer profiling. ${ }^{8}$ All this contributes to create a totally novel media environment that dramatically reduces the boundaries between "mass media" and "personal communication", presenting the almost unsurmountable difficulty of devising proportionate regulatory policies that can compose these forms of communication together.

As a consequence, the last few years have witnessed "a shift from widespread acceptance of a principle of limited liability for Internet companies, to ever-increasing calls for interme-

\footnotetext{
5 The media's intrinsic editorial practices have diversified, adopting new modalities, procedures and outcomes. New actors have assumed functions in the production and distribution process of media services which, until recently, were only (or mostly) performed by traditional media organisations; these include content aggregators, application designers and users who are also producers of content. In comparison with a not-too-remote past, nowadays the media environment is overturned: as already acknowledged by the Council of Europe Recommendation CM/Rec(2011)7 on a new notion of media.

6 'World Trends in Freedom of Expression and Media Development: Global Report 2017/2018

- UNESCO Digital Library' 25 <https://unesdoc.unesco.org/ark:/48223/pf0000261065> accessed 7 December 2020.

7 For a detailed analysis on the role of digital intermediaries, see Martin Moore and Damian Tambini (eds), Digital Dominance (Oxford University Press 2018). See also, Nicolas Laurent Bernard Max Petit, Big Tech and the Digital Economy: The Moligopoly Scenario (Oxford University Press 2020); Martin Moore, 'Tech Giants and Civic Power' <https://kclpure.kcl.ac.uk/portal/en/publications/tech -giants-and-civic-power(b8e837ec-abd8-4838-b8e7-f0059f0de550).html > accessed 20 December 2020.

8 Manuel Castells, Communication Power by Manuel Castells (2nd edn, Oxford University Press 2009).
} 
diaries to be more active as mediating gatekeepers". ${ }^{9}$ Acknowledging that platforms are not media in the traditional sense and most often refuse to recognise editorial responsibility on the content they disseminate, but also considering their impact on public opinion, the academic and policy debate is heated on how to define a proportional and fair regulatory framework for these intermediaries. Internet intermediaries have been assimilated, in the e-Commerce directive, to Internet Service providers (ISP), thus ensuring them a substantial immunity from content's regulation: the political debate on platforms' regulation vastly oscillates from the one extreme of considering them almost neutral carriers of third parties' content to the other extreme of holding them liable for any kind of illegal and/or harmful content they may carry. The final choice on the duties and liability imposed on platforms most likely will be decisive in reshaping the regulatory intervention and antitrust rules to be applied to all their activity. ${ }^{10}$

Against this backdrop, an obvious potential "victim" of the gatekeeper role of platforms is the notion of media pluralism associated with the pre-existing role of media. Historically, given the key role they play in supporting democratic processes, the mass media were subject to extensive national regulation, primarily aimed at guaranteeing some kind of media pluralism. Theories and conceptualisations of "media pluralism" stem from the need to respond to a mass media environment characterised by concentrated markets, and on account of requests for "diversity" within traditional press and broadcasters. The genesis of traditional policies on media pluralism is therefore linked to that print-based and linear broadcasting environment that has lost its centrality. ${ }^{11}$ In the past, the obvious distinction between mass media and personal communication was the pillar for different regulations and policies, including on pluralism. The challenges of a "new media" environment characterised by audience segmentation, proliferation of personalised information services, and algorithmic-driven communication based on consumer profiling appear completely different. Regulatory strategies based on the different impact on public opinion of a "public at large" communication and of personal communication (i.e., messages with specific and limited "recipients") need to be revisited, based on an approach that requires a "graduated and differentiated response". ${ }^{22}$ While it is widely acknowledged that plural information is essential to ensure the integrity of democratic processes, the essential question is what type of communication can be considered relevant to public discourse, and what should be measured when assessing the level of pluralism of the digital media environment. The answer to this question is one of the keys of the European media law and policy we attempt to explain in the Handbook.

As anticipated, we proceed by successive approximations to reach the core of the matter regarding EU media regulation. The first step is to explore the exact scope of the European Union remit and the legal basis for legislative intervention of the EU when it comes to media. It is widely acknowledged that the European Union has scattered immediate competences

9 'World Trends in Freedom of Expression and Media Development: Global Report 2017/2018

- UNESCO Digital Library' <https://unesdoc.unesco.org/ark:/48223/pf0000261065> accessed 7 December 2020.

${ }_{10}$ The debate is developing around the important Proposal for a regulation of the European Parliament and of the Council on contestable and fair markets in the digital sector (Digital Markets Act) Brussels, 15.12.2020, COM(2020) 842 final, 2020/0374(COD)

11 Elda Brogi, 'The Media Pluralism Monitor: Conceptualizing Media Pluralism for the Online Environment' (2020) Profesional de la información, v. 29, n. 5, e290529 < https://doi.org/10.3145/epi .2020.sep.29>.

12 Recommendation $\mathrm{CM} / \operatorname{Rec}(2011) 7$ on a new notion of media. 
in the field of media because member states, at least for a long time, essentially resisted any direct EU regulation of many aspects of media policy, including media freedom and pluralism. Nevertheless, it is clear that the EU considers media, media freedom and pluralism themselves to be core democratic values. In fact, they form part of the essence for the rule of law,,$^{13}$ and are key ingredients for accessing membership to the Union. ${ }^{14}$ However, the remit for affirming these essential principles is not explicit in the EU Treaties, being already enshrined in the common constitutional traditions of member states. ${ }^{15,16}$ The Charter of Fundamental Rights of the European Union, now part of the Treaties, after it was included in the Lisbon Treaty, embodies freedom and pluralism of the media. Nonetheless, the inclusion, as explicitly mentioned by article 6 TEU, does not extend the competences of the Union as defined in the Treaties.

While the Treaties do not provide the EU with explicit powers in the field of media, in recent decades, the European Union's intervention in the media sector, although mainly moving from economic reasons, has been anyway significant. In particular, the need and the aim to foster a European single market for media services, justified under the freedom to provide services, has constituted a powerful driver of intervention. ${ }^{17}$ For instance, the application to Public Service Media (PSM) of European competition and state aid rules has been important for the evolution of the public broadcasting in member states. This process, in the end, has acknowledged not only economic but also democratic, social and cultural needs of each country, including the need to preserve media pluralism. Furthermore, electronic communications, today a major means to convey content, have been subjected to very detailed rules with a specific impact on media distribution. Also, EU copyright legislation is inevitably linked with the media sector, framing one of the relations (and of the conflicts) between traditional media and

13 See the report of the High level group on media pluralism and freedom, A free and pluralistic media to sustain European democracy 'HLG Final Report.Pdf' < https:/ec.europa.eu/digital-single-market/ sites/digital-agenda/files/HLG\%20Final\%20Report.pdf $>$ accessed 8 December 2020. Communication -2020 Rule of law report - the rule of law situation in the European Union $<$ https:/ec.europa.eu/info/ publications/2020-rule-law-report-communication-and-country-chapters_en $>$.

14 Elda Brogi, Alina Dobreva and Pier Luigi Parcu, Freedom of Media in the Western Balkans (2014) $<$ https://cadmus.eui.eu//handle/1814/39557> accessed 8 December 2020.

15 CMPF, European Union competencies in respect of media pluralism and media freedom, EUI RSCAS PP, 2013/01, Centre for Media Pluralism and Media Freedom (CMPF). Retrieved from Cadmus, European University Institute Research Repository, at: <https://cadmus.eui.eu//handle/1814/26056> accessed 8 December 2020; Elda Brogi, Pier Luigi Parcu, 'The evolving regulation of the media in Europe as an instrument for freedom and pluralism', EUI RSCAS, 2014/09, Centre for Media Pluralism and Media Freedom (CMPF) [Communications and Media]. Retrieved from Cadmus, European University Institute Research Repository, at <http://hdl.handle.net/1814/29923>.

16 The EU has competencies on culture, which include the support to the audiovisual sector, see Evangelia Psychogiopoulou, Cultural Governance and the European Union: Protecting and Promoting Cultural Diversity in Europe (Palgrave Macmillan 2015) and Rachael Craufurd Smith, Culture and European Union Law (Oxford University Press 2004).

17 On this legal basis, broadcasting has been falling - at least for certain aspects - under the EC Treaty umbrella since a 1974 European Court of Justice judgment (the Sacchi case). According to ECJ case-law, in fact, broadcasting must be interpreted as a "service" covered by the Treaties' discipline: "In the absence of express provision to the contrary in the Treaty, a television signal must, by reason of its nature, be regarded as provision of services. ... It follows that the transmission of television signals, including those in the nature of advertisements, comes, as such, within the rules of the Treaty relating to services". For a detailed analysis on EU competences and legislation in the broadcasting sector see Peggy Valcke and Katrien Lefever, Media Law in the European Union (Wolters Kluwer Law \& Business 2012). 
new gatekeepers. This is just to list some of the main fields that are touched by a variety of European legislative competences and significantly affect EU media and its regulation.

On the other hand, partly due to its generic legal basis, the only media specific Directive adopted by the EU has never been considered a good example of legislation. A lack of generality has influenced the approval of the first European Directive "Television without frontiers" in 1989 (including the 1997 amendments), and its developments into the Audiovisual Media Services Directive approved in $2007^{18}$ and amended in $2018 .{ }^{19}$ In a limited scope, through the harmonisation of national laws, it has progressively regulated certain well identified areas, like commercial communication, protection of minors, and right of reply. Today, in light of the increasingly difficult definition of media that was acknowledged above, even these scant specific rules on media appear insufficiently defined. The structural developments of the media market and the myriad of flourishing new online services that entertain and inform users expose old media to many potential competitors. In order to cope with new trends in the market, most recent reforms of the Directive have progressively widened the scope to include non-linear services ${ }^{20}$ and the amended AVMSD has provided another rationale for interpreting "media-like" services in a broader sense. Lately, with the inclusion of the Video Sharing Platforms (VSP) in the AVMSD, even if not fully assimilating the regulation of these services to audiovisual ones, and without prejudice to the e-Commerce directive, ${ }^{21}$ the EU has started a new frontier for EU media law and opened a "regulatory laboratory" to define future trends in content moderation and curation. In the end, this may turn out as an interesting path for defining and regulating new forms of "hybrid media (AV) services" distributed by online platforms. However, it is likely that these regulatory innovations will not be easy to achieve.22 In any case, the Directive, with all its limits, is a pillar of the European Union regulation of audiovisual media. The expansion of its scope across the decades, to include a broader notion of audiovisual media services (linear and non-linear), and especially the recent introduction of Video Sharing Platforms, is a possible direction to define a new generation of rules.

Following the digital disruption, EU jurisdiction on media has the occasion and the necessity to be reconstructed and rebased on the complex and global nature of "media" services in the single digital market. It must also be acknowledged that, pending the publication of the

18 Directive 2007/65/EC of the European Parliament and the Council of 11 December 2007 amending Council Directive 89/552/EEC on the coordination of certain provisions laid down by law, regulation or administrative action in Member States concerning the pursuit of television broadcasting activities (later codified with Directive 2010/13/EU).

19 Directive (EU) 2018/1808 of the European Parliament and of the Council of 14 November 2018 amending Directive 2010/13/EU on the coordination of certain provisions laid down by law, regulation or administrative action in Member States concerning the provision of audiovisual media services (Audiovisual Media Services Directive) in view of changing market realities.

20 Peggy Valcke and Eva Lievens, Rethinking European broadcasting regulation: the audiovisual media services directive unraveled at the dawn of the digital public sphere in Caroline Pauwels, Harri Kalimo and Karen Donders, Rethinking European Media and Communications Policy (Asp/Vubpress/ Upa 2009).

${ }_{21}$ See "whereas" arts 47 and 48 and art 28 b of the 2018 AVMS Directive.

22 It must be noted that, pending the publication of the Handbook, the European Commission started infringement procedures against 23 member states out of 27 for the delays in transposing the rules of the Directive into national legislations. While a difficulty may stem from many different causes, including the COVID-19 pandemic, it is likely that a cause is the regulatory complexity, also in terms of governance, that the implementation of the Directive apparently entails. 
Handbook, the European Union is preparing to initiate the process of a major reform for the Digital Market as a whole, including a deep revision of the e-Commerce directive. This alteration will take into account the developments of the last two decades and update the horizontal regulatory framework for all digital services in the single market, including online platforms and their decisive gatekeeper's role. ${ }^{23}$ Considering the transnational nature of online "media" and "information" services, the debate on media pluralism, and its evolving meaning in the age of information abundance, finds its clear collocation at the European level. Strictly connected with fundamental freedoms and democracy, media regulation, at the EU level, emerges to pursue fundamental values. Media pluralism (or better, information pluralism) and media freedom assert themselves as policy goals that are essential for democracy and human rights in all Europe, particularly when addressing an increasingly global hybrid media environment that is too big for an effective reach of national member states.

The relevance given by the European Commission to these themes is confirmed by the efforts it is putting into defining a sound policy to limit the spread of disinformation in the online environment. Perceived as an existential threat to the integrity of democracy, online disinformation is one of the objects of European policy efforts towards online digital platforms. The EU is trying to tackle the spread of disinformation online also by progressively building specific European standards based on an evolving concept of media pluralism for the new era.

As this is a process, it must be acknowledged that the future will certainly reserve many changes and reforms of the so-called "EU media law". Pending the publication of the Handbook, the European Commission is not only engaging in the broad aforementioned revision of the e-Commerce directive, but also re-evaluating the current "digital" policies and laws that should lead to a new regulatory framework more in line with fundamental rights. Within the same set of proposals, the Commission is fostering policies to raise the bar for the respect of the rule of law in the EU, including media pluralism. ${ }^{24}$ As mentioned, with the first report and the purpose of starting a regular analysis on it, the European Commission is initiating a new strategy to strengthen the respect of the rule of law in EU member states. ${ }^{25}$ The rule of law is enshrined in Article 2 of the Treaty on European Union as one of the common values for all Member States, and in the preambles to the Treaty and to the Charter of Fundamental Rights of the EU. Moreover, under Article 49 TEU, the respect for the rule of law is a precondition for EU membership.

Media pluralism and freedom is recognised in the first rule of law report as one of the pillars on which the analysis is based, along with: the independence of the national justice systems, a valid anti-corruption framework, and other institutional issues related to the checks and

23 Proposal for a Regulation of the European Parliament and the Council on a Single Market For Digital Services (Digital Services Act) and amending Directive 2000/31/EC, Brussels, 15.12.2020 COM(2020) 825 final 2020/0361(COD), <https://eur-lex.europa.eu/legal-content/EN/TXT/HTML/?uri $=$ CELEX:52020PC0825\&from $=$ en $>$ accessed 8 December 2020 .

24 Communication from the Commission to the European Parliament, the Council, the European Economic and Social Committee and the Committee of the Regions On the European democracy action plan COM(2020) 790 final <https://eur-lex.europa.eu/legal-content/EN/TXT/HTML/?uri=CELEX: 52020DC0790\&from $=\mathrm{EN}>$.

25 Communication from the Commission to the European Parliament, the Council, the European Economic and Social Committee and the Committee of the Regions COM(2020) 580 final, Rule of Law Report. The rule of law situation in the European Union <https:/eur-lex.europa.eu/legal-content/EN/ TXT/HTML/?uri=CELEX:52020DC0580\&from=EN> accessed 8 December 2020. 
balances essential to an effective system of democratic governance. In conclusion, whether media pluralism per se cannot be seen as a direct legislative competence of the EU based on the treaties, it is nevertheless becoming a crucial element in the definition of the identity of the European Union and in a process of building the EU as a space of democracy and shared common values.

\section{PRESENTATION OF THE CONTRIBUTIONS}

The Handbook attempts to unpack the complexities and paradoxes of decision-making processes and policies within the media sector in the EU by engaging with the various dimensions of media law and policy and beyond. Ranging from the harmonisation process of EU media law and the enforcement of the Audiovisual Media Services Directive (AVMSD) at the national level, to the protection of media freedom and media pluralism in the EU, the four parts of the Handbook collectively shed light on the importance of these different dimensions for the proper regulation of this key sector of the economy and the society. The aim of the Handbook is not to cut out a sharp definition of "media" and provide a consequently definite description of EU media law, but rather to describe the process of defining a new regulatory framework for a sector that is evolving.

This is why in sketching the foundations of EU policies in the media sector in Part I, the Handbook first uses an unconventional approach to reflect on the meaning and conceptualisation of media pluralism in the digital age. It uses the experience of the Media Pluralism Monitor (MPM) project (Elda Brogi, Roberta Carlini, Iva Nenadic, Pier Luigi Parcu and Mario Viola de Azevedo Cunha) as a starting point. The MPM is a tool designed to assess the risks for media pluralism in EU member states (and beyond), based on a vast set of indicators that cover legal, economic, and socio-political aspects. The research and results of the MPM assessment have been recognised by the EU as a relevant and integral source for assessing the pillar on media pluralism and freedom in the Rule of law report.

As previously mentioned, the largest foundations of EU media jurisdiction need to be reconstructed, starting from its scattered legal basis, and this chapter sketches the legal grounds on which the actions of the European Union are based. In fact, the whole core of Part I of the Handbook is devoted to the analysis of the wide legal basis for the EU action, moving from the ones hidden under different provisions of the Treaties. Taken together, they may be seen as forming that general frame that allows one to identify a sort of media's "acquis communautaire", which is difficult to notice at first sight.

Starting from the cultural realm, Evangelia Psychogiopoulou, provides a thoughtful analysis of the cultural dimension of EU legislative action in the audiovisual field, delving into the operationalisation of EU audiovisual policy by the AVMSD. The author reveals that cultural diversity gradually became one of the EU audiovisual policy's main objectives and points out several provisions of the revised AVMSD that can be viewed from a cultural perspective. These include the rules on events of major importance for society and of high interest to the public; the rules on respect and promotion of human dignity which proscribe audiovisual media services that contain incitement to violence or hatred directed against a group of persons or a member of a group based on the grounds referred to Article 21 of the Charter of Fundamental Rights of the Union; and the rules on ensuring "appropriate prominence of audiovisual media 
services of general economic interest" or those meant to guarantee the integrity of programmes and of audiovisual media services.

Given that the media sector is an economic one, it is required to follow EU competition rules. Anna Pisarkiewicz and Michele Polo investigate the relation between competition and the media in the EU and examine provisions in competition law that affect the media sector. Their inquiry sheds light on the relevant problem of concentration in media markets. They review the main tools of merger assessment in media markets from an antitrust perspective while adequately underlying the specific features of media operators and markets. They also focus on the issues introduced by new media and their competition with the old ones, and discuss the complementariness and divergence of possible different lines of intervention.

As stated in the relevant Protocol annexed to the Amsterdam Treaty, ${ }^{26}$ "the system of public broadcasting in the Member States is directly related to the democratic, social and cultural needs of each society and to the need to preserve media pluralism", while its funding should not affect trading conditions and competition. Moving from the issue of how the EU has shaped the provision of public service broadcasting and online public media services, Rachael Craufurd Smith explores the various, inter-related, frames of reference used to anchor public service broadcasting within the field of EU law. Craufurd Smith specifically reconstructs the changing focus of EU engagement with Europe's public service media over time: starting from the original competition and state aid prevailing concerns, to the steps taken by the EU to support and strengthen the legitimacy and effectiveness of public service media with reference to fundamental rights and freedoms.

Finally, Federica Casarosa evaluates the importance and the impact of judicial interactions as a means to achieve the harmonisation of EU media law. She acknowledges recent technical developments as one of the new challenging features for the media sector, including "the creative use of technology by its users as well as the trend towards convergence across media". The author illustrates her hypothesis by analysing some key decisions of the Court of Justice of the European Union (CJEU) on the material scope of application of the AVMSD and on the definition of hate speech.

In Part II the Handbook addresses the relationship between the various aspects of the Digital Single Market and media law and policy. In particular, it covers parts of the EU legislative framework that, while still not directly linked with the regulation of media content (as the AVMSD, examined in Part III), appear to be more strictly related to it.

The contribution of Alexandre de Streel and Christian Hocepied opens this section of the Handbook with an analysis of the revised EU regulatory framework for electronic communications networks. Electronic communications constitute the technical structure for any service provided by traditional and new media services. The authors provide a thorough analysis of the regulation, ranging from its objectives, principles and institutional set-up, to the rules that govern market entry, promote competition, define universal service and impose must carry obligations.

${ }_{26}$ Treaty of Amsterdam amending the Treaty on European Union, the Treaties establishing the European Communities and certain related acts - Protocol annexed to the Treaty of the European Community - Protocol on the system of public broadcasting in the Member States <https://eur -lex.europa.eu/legal-content/EN/TXT/HTML/?uri=CELEX:11997D/PRO/09\&from=EN $>$ accessed 8 December 2020. 
Giovanni Sartor, in turn, analyses the economic and social role of Internet intermediaries and explores the complex and crucial interpretation of articles 12-15 of the e-Commerce directive on ISPs' liability. He provides an overview of the directive's relevant rules, addressing the hot topic of the secondary liability of Internet intermediaries; namely, the issue of whether and to what extent, intermediaries should be liable for illegal activities by their users. As formerly mentioned, the issue is particularly relevant when defining the boundaries between different types of operators on the Internet and on the web. The author also compares the regulation of intermediaries' secondary liability in the US and in the EU e-Commerce directive. He discusses the main issues related to the application of the Directive and suggests overdue and imminent reforms.

In a strictly related contribution, Marta Maroni and Elda Brogi explore the nature of online intermediaries providing an overview of how the Court of Justice of the European Union has applied and further specified the concepts of neutrality and the absence of monitoring obligations contained in the e-commerce directive, thus contributing to the definition of "intermediary". The chapter concludes by providing an analysis of the recent developments regarding the role of digital platforms adopted within the EU legal framework. The boundaries between the application of the e-Commerce directive rules on intermediary liability and the application of other rules, e.g. on copyright, data protection or video sharing platforms, when online intermediaries are at stake, are progressively reshaping the regulatory approach to media-like services, posing questions of reasonability and proportionality of ad hoc legislative interventions when defining rules that are applied differently for similar online services. More coherence across EU legislation is needed in these cases, in particular considering the interest at stake that justify the different level of liability for similar services.

New technologies can be used either to hinder or to boost the growth of the digital single market. Geo-blocking is one example of business practices limiting access to online services based on customers' location. Giovanni De Gregorio's chapter explores the case of geo-blocking and its discriminatory aspects and addresses the specific EU regulation on geo-blocking and its role in the Digital Single Market strategy.

Another very important component to be considered as part of the EU media law framework is provided by copyright rules. Giuseppe Mazziotti delves into the role of EU copyright law for broadcasters in supporting cultural creation and ensuring cultural diversity. The author clarifies the role of EU copyright law for broadcasters in a fast-changing audiovisual sector, assessing how EU law evolved in pursuing its goals at a time when TV-like services, video-on-demand providers and social media platforms give access to the same works and compete with each other to attract the same audiences.

A major theme that is intertwined with the media and information sector is data protection: the digital economy is fuelled by data, the "new oil". ${ }^{27}$ Mario Viola and Shara Monteleone explore how the emergence of data-driven services and products has shaped the relationship between data protection and other fields of law, namely consumer law and competition law in the Internet and media market. Consequently, it also impacts the relationship between freedom of expression and data protection rights. The authors also discuss the interplay between these

27 The Economist, 6 May 2017, 'The world's most valuable resource is no longer oil, but data' $<$ www.economist.com/leaders/2017/05/06/the-worlds-most-valuable-resource-is-no-longer-oil-but -data $>$ accessed 8 December 2020. 
rights as a consequence of the implementation (or the lack of) specific legislation in the field of data protection.

Finally, Roberta Carlini, addresses a different, but nevertheless crucial challenge for media policy that arises from digitalisation. Through studying its impact upon EU fiscal policy, she overviews the international debate on digital taxation at OECD and at EU level, focusing on the eventual direct and indirect impact of digital taxation reform on the media market and media viability. Addressing the need of a regulatory intervention, Carlini's conclusion is that a fiscal reform could produce a more even market and encourage balanced regulation. It would also be beneficial to earmark part of the revenue from a digital tax to actively fund and enhance media pluralism at EU level.

As already mentioned, Part III concentrates on the more limited and clearly delineated legal framework that at present directly regulates certain elements of the media sector in the EU. The focus of this part is necessarily all dedicated to the amended Audiovisual Media Services Directive (AVMSD).

Sally Broughton Micova starts by addressing the background rationale of the AVMSD. She presents it as a unique blend of the barrier lifting liberal market approach, typical of the EU's single market, and classic protectionism, stemming from a history of concern that US content and media services would dominate European screens. The author traces and discusses these contradictory roots of the AVMSD, and examines the core elements of the Directive and the extent to which they have been adapted over time. She convincingly demonstrates that encouraging European audiovisual production and consumer protection have been the main concerns, while so far, freedom of expression or media pluralism has never been central to the legal evolution.

Two chapters are dedicated to the analysis of the definition and the rules for "Video Sharing Platforms", one of the main novelties in the amended AVMSD, that acknowledges the evolving digital audiovisual landscape and proposes new regulatory approaches. Peggy Valcke and Ingrid Lambrecht's chapter recapitulates the main elements of the definition of "audiovisual media service" and the changes introduced by the amended AVMSD. It unravels the new definition of video-sharing platform and clarifies what does and does not fall within its scope. The success and the pitfalls in the adaptation of the Directive to a changing digital environment is the important primary focus of the chapter.

Lubos Kuklis, on the other hand, enriches the debate on content regulation on digital platforms by directly and specifically addressing the meaning and relevance of the novel video-sharing platforms regulation under the AVMSD. He discusses the systemic approach adopted by the AVMSD as well as the rights of uses and transparency, arguing that the latter two may prove to be crucial in the development of a new approach to content regulation on digital platforms, and bets they will be increasingly necessary in the near future.

Ernesto Apa and Giovanni Gangemi further expand the regulatory aspects of the audiovisual media sector, concentrating on the promotion of European works by audiovisual media service providers. The authors particularly explore the regulatory framework for on-demand and linear services under the AVMSD, discussing the adoption of more stringent rules for on-demand services as a way to reduce past regulatory asymmetry between the two service categories.

In the final chapter of this part, Adriana Mutu, moving to a governance perspective of the sector, analyses the background conditions for the requirement of National Media Regulatory Authorities (NRAs) as provided for in Article 30 of the amended AVMSD. By highlighting 
the importance of independence as an "institutional value" and a central principle of good governance, the author compares and discusses the provisions for regulatory independence of National Media Regulatory Authorities under the previous AVMS and its amended version.

Part IV of the Handbook returns to a broader concept of EU Media Policy for the digital times. It highlights a list of problematic areas currently debated by academics and policy makers in Europe and collects contributions that especially analyse EU efforts to protect media freedom and promote media pluralism.

The Media Pluralism Monitor project, already described in Part I, offers a suitable starting point for this endeavour. This part of the Handbook compares the MPM with two reports and indices about the state of the freedom of expression, freedom of the media and media independence that are produced by specialised organisations. The two most well-known ones are published by the NGOs, Reporters Without Borders (RWB) and Freedom House (FH). Their indices are influential, much quoted in policy documents, and having impact on the formation of international relations. Elda Brogi, Pier Luigi Parcu and Iva Nenadic start their chapter by elaborating how these NGOs produce indices that rank countries worldwide according to different sets of indicators related to freedom of expression and freedom of the media. As a second step, they compare the existing indices with the Media Pluralism Monitor ranking of European Union Member States, Montenegro and Turkey, conducted by the CMPF at the EUI. While the RWB and FH indices, at least in the results, appear very similar, showing very strong correlations, the MPM produces clearly distinguishable information from the other indices for the EU and beyond, thereby providing a unique and autonomous new source of information on media pluralism, relevant both for policy analysis and academia.

The MPM results are used by Beata Klimkiewicz to analyse policies on community media and minorities' access to media. In her chapter, she argues that communities' chances to gain direct access to the media, including the conditions of the so-called "third media sector" (media produced for and/or by minorities), may be understood as indications of media inclusiveness, and more generally of media pluralism. The chapter presents policies of European and international institutions concerning community media and minorities' access to the media, and goes on assessing the situation in individual countries. Using data from the MPM, it displays that access to media for minorities is one of the highest risk-level indicators. The data shows that despite improvements and repeated attempts to address the issue at the level of European policies, the situation in the member states is still not satisfactory.

The European Union institutions and their political and financial mechanisms play an essential role in shaping the media systems of countries applying for EU membership. Media freedom is high up on the EU enlargement policy agenda. In fact, the funds allocated to the pre-accession Civil Society Facility and Media Programme have significantly increased, and notable amounts of funding were made available to support, among others, bodies for media self-regulation and investigative journalistic activities. However, in their chapter, Brankica Petković and Sandra B. Hrvatin, point out that the actual process of EU media-assistance has not always been without problems. They argue that the EU appears lacking a coherent media policy. Instead, its non-binding, mutually referent documents on media apply only loose definitions with the primary aim of protecting economic interests. References to the freedom of expression as a basic human right, for the authors, come without clear demands to effectively protect the rights of people.

High up on the policy agenda, we find the issue of the spread of "disinformation". Although numerous documents have been published on the topic, for now we are still short of a clear 
enough definition of misinformation and disinformation. While we know for sure that the phenomenon poses a threat to a number of human rights, Pier Luigi Parcu and Maria Luisa Stasi highlight the need to further explore how exactly it affects the media industry, individual users and the wider society. Tackling the phenomenon implies the ability to strike a balance among the different rights and public and private interests involved. Currently, one of the most widely accepted proposals is to impose obligations on platforms to remove suspicious content; however, this approach can easily infringe on the right to free expression through over-removal, and the ensuing self-censorship of users. The task would be better performed by courts than by regulators or private actors, but this vast phenomenon requires too fast a response to be effectively tackled by courts alone. After reviewing some of the current practices, the authors recommend a diverse set of actions by all stakeholders involved in order to transcend the narrowly focused measures that rarely go beyond addressing the symptoms. First of all, governments have the responsibility to establish an adequate framework to ensure plurality and diversity of information, incentives to limit disinformation, and to support (digital) media literacy in our society. Secondly, companies have to implement measures that contrast the phenomenon, without this leading to general monitoring or other measures that unduly restrict individuals' freedom of expression. And finally, users have to do their part too. This is why it is essential for any effective action to look for solutions that increase users' awareness and empower them.

Finally, Pier Luigi Parcu and Maria Alessandra Rossi conclude the Handbook with an overview of developments that shaped both the way in which media contents were produced, and consumed, in the last two decades. They also explain how digitisation and platformisation of the economy have led to profound changes in access to news and information, walking the reader through the diverse policy concerns, which emerge from the supply-side of news production and distribution, as well as from the demand-side of news consumption. The apparent richness of information sources conceals serious threats to the quality and diversity of online news, available on global platforms devoid of editorial responsibility and interested solely in maximising advertising revenue. The authors show that today's preferred policy proposal, emphasising the self-regulation of platform distribution content, has strong limitations, among others due to the fact that platforms were so far unable to identify specific benchmarks that enable the tracking and measurement of progress related to these efforts. Their own conclusion suggests three preferred lines of possible policy intervention in defence of media pluralism: regulated transparency, a novel form of stable and reliable EU-level direct financing, as well as enhanced market power oversight.

The Handbook gathers contributions from reputed scholars and expert stakeholders in the media sector working in different areas of media law and policy, thus offering readers a vast overview of the current legislation, policies and challenges surrounding media and their regulation in the EU.

It must be stressed that the topics analysed by the chapters of the Handbook are not fully comprehensive of all the aspects that may be considered part of "EU media law and policy", as there are many more. The challenge of this Handbook is, therefore, to give evidence of how the sector is evolving, and to acknowledge the complexity of the development of regulatory and policy responses to a digital environment in full expansion.

We do gratefully thank, first, the authors of the Handbook for their valuable contributions, the European University Institute in Fiesole for providing the ideal intellectual environment for this multidisciplinary effort, the Centre for Media Pluralism and Media Freedom team for 
14 Research handbook on EU media law and policy

developing together the essential MPM tool and Dr Danielle Borges for the support in revising and assembling the chapters. 